\title{
Optimal Active Power Control of A Wind Farm Equipped with Energy Storage System based on Distributed Model Predictive Control
}

\author{
Zhao, Haoran; Wu, Qiuwei; Guo, Qinglai; Sun, Hongbin; Xue, Yusheng
}

Published in:

IET Generation Transmission and Distribution

Link to article, DOI:

10.1049/iet-gtd.2015.0112

Publication date:

2016

Link back to DTU Orbit

Citation (APA):

Zhao, H., Wu, Q., Guo, Q., Sun, H., \& Xue, Y. (2016). Optimal Active Power Control of A Wind Farm Equipped with Energy Storage System based on Distributed Model Predictive Control. IET Generation Transmission and Distribution, 10(3), 669 - 677. https://doi.org/10.1049/iet-gtd.2015.0112

\section{General rights}

Copyright and moral rights for the publications made accessible in the public portal are retained by the authors and/or other copyright owners and it is a condition of accessing publications that users recognise and abide by the legal requirements associated with these rights.

- Users may download and print one copy of any publication from the public portal for the purpose of private study or research.

- You may not further distribute the material or use it for any profit-making activity or commercial gain

- You may freely distribute the URL identifying the publication in the public portal 


\title{
Optimal Active Power Control of A Wind Farm Equipped with Energy Storage System based on Distributed Model Predictive Control
}

Haoran Zhao

PostDoc, Department of Electrical Engineering, Technical University of Denmark, Lyngby, Denmark

Email:hzhao@elektro.dtu.dk

Qiuwei $W u^{*}$

${ }^{*}$ Corresponding author

Associate Professor, Department of Electrical Engineering, Technical University of Denmark, Lyngby, Denmark

Email:qw@elektro.dtu.dk

Qinglai Guo

Associate Professor, Department of Electrical Engineering, Tsinghua University, Beijing, China

Email: guoqinglai@tsinghua.edu.cn

Hongbin Sun

Professor, Department of Electrical Engineering, Tsinghua University, Beijing, China

Email: shb@tsinghua.edu.cn

Yusheng Xue

Professor, State Grid Electric Power and Research Institute, Nanjing, China

Email: xueyusheng@sgepri.sgcc.com.cn

\begin{abstract}
This paper presents the Distributed Model Predictive Control (D-MPC) of a wind farm equipped with fast and short-term Energy Storage System (ESS) for optimal active power control using the fast gradient method via dual decomposition. The primary objective of the D-MPC control of the wind farm is power reference tracking from system operators. Besides, by optimal distribution of the power references to individual wind turbines and the ESS unit, the wind turbine mechanical loads are alleviated. With the fast gradient method, the convergence rate of the DMPC is significantly improved which leads to a reduction of the iteration number. Accordingly, the communication burden is reduced. Case studies demonstrate that the additional ESS unit can lead to a larger wind turbine load reduction, compared to the conventional wind farm control without ESS. Moreover, the efficiency of the developed D-MPC algorithm is independent from the wind farm size and is suitable for the real-time control of the wind farm with ESS.
\end{abstract}

Index Terms- D-MPC, ESS, mechanical load, wind farm control. 


\section{Introduction}

Wind power has achieved rapid development due to the ambitious goal of renewable energy deployment and increase of energy demand. With large-scale wind power integration, wind farms are required to meet the more stringent technical requirements specified by Transmission System Operators (TSOs) [1], [2]. Wind farms may produce less active power than the available wind energy and the extra wind energy can be bid into the reserve market and the wind farm can get compensation by offering regulating services to TSOs [3].

With the flexible charging-discharging characteristics, Energy Storage System (ESS) is considered as an effective tool to enhance the flexibility and controllability of a wind farm. The ESS type selection for the wind farm is dependent on the control purposes [4]. Fast and short (or medium) term ESS can be used for power quality improvement and frequency control, while slow and long term ESS is more suitable for economic dispatch [5]. In this paper, the fast and short-term ESS unit, such as Battery, Super-capacitor, etc., is utilized in a wind farm for its fast response and the real time operation control purpose of the wind farm. The control objective of the ESS is to compensate the power mismatch between the reference value and the actual output of the wind farm, and alleviate the mechanical load of wind turbines.

The wind turbine mechanical load (load for short hereinafter) refers to the forces and moments experienced by the wind turbine structure, which has a significant effect on the service lifetime of wind turbines [6]. It was initially introduced as an additional control objective to the control of the wind farm without ESS. Since the wind farm may be required to produce less than the maximum available power, the wind turbines operate in the derated mode and have regulation freedom. As long as the power demand is met, the wind farm controller can optimally distribute the power set-points to the wind turbines for load minimization. The additional ESS can be considered as an actuator, which is capable of providing fast and flexible power charge-discharging. As such, the regulation freedom of individual turbines is enhanced. Accordingly, the load alleviation performance can be improved.

Several modern control schemes were proposed to exploit this power distribution freedom of wind turbines [7][14]. Among them, Model Predictive Control (MPC) is considered as a good option to handle the multi-objective optimization problem. The application of MPC for wind farm is a relatively new research field. In [9], a MPC controller was designed to improve the wind farm participation to frequency regulation. Beside the wind turbine model, the network primary frequency model was also included. A Nonlinear MPC (NMPC) was proposed in [10] for minimizing the wind farm wake loss and optimizing the captured power. In [11], the MPC was used to track a desired power reference from TSO accurately and smoothly without consideration of wind turbine loads. [12]-[14] dealt with tracking a desired output and load alleviation of the whole wind farm. The formulated MPC problem was explicitly solved offline by the multi-parametric programming. The control object of the references above is wind turbine. In [15], [16], the MPC application was extended to the wind farm equipped with an ESS unit. The 
ESS is used to improve the dispatchability of the wind farm and has no contribution to the wind turbine load alleviation. Moreover, the MPC problems proposed in the aforementioned references were solved in a centralized manner, so-called Centralized MPC (C-MPC). With the increasing number of wind turbines, the order of the wind farm model grows drastically and the computation burden becomes very heavy which makes the C-MPC impractical for real-time applications.

This paper presents a Distributed MPC (D-MPC) control scheme of a wind farm and the ESS unit which aims to track the power reference and minimize the wind turbine load. The contributions of the paper are twofold. Firstly, the optimization control problem of the wind farm equipped with an ESS is formulated. The charging and discharging of the ESS is considered as decision variables to optimize the ESS operation. Secondly, to efficiently solve the formulated optimal control problem, the D-MPC algorithm is applied. The parallel generalized fast dual gradient method proposed in [17], [18] is adopted to design the wind farm D-MPC controller.

The paper is organized as follows: The modeling of the wind turbine and the ESS unit is introduced in Section 2. Section 3 describes the wind farm controller based on the D-MPC. Section 4 presents the design of the D-MPC for a wind farm with an ESS unit. Case studies are presented and discussed in Section 5 followed by conclusions.

\section{Modeling of wind turbine and ESS unit}

In this section, the discrete models of a single wind turbine and an ESS unit are described which are used as prediction models for the D-MPC .

\subsection{Modeling of Wind turbine}

A nonlinear variable speed pitch-controlled wind turbine system is shown in Fig. 1. To reduce the computation complexity, a simplified wind turbine prediction model introduced in [12] is adopted.

In this model, the fast electromagnetic transients are neglected. The torque control is assumed to be ideal and generator efficiency $\mu$ is compensated in the WTG controller. Accordingly, the power production $P_{\mathrm{g}}$ can be considered as equal to the reference $P_{\text {ref }}^{\mathrm{WT}}$. The state-space form of the model around an operating point is expressed as,

$$
\begin{aligned}
& \dot{x}=A x+B u+E d \\
& z=C x+D u+F d
\end{aligned}
$$

where $x=\left[\theta, \omega_{\mathrm{r}}, \omega_{\mathrm{f}}\right]^{\prime}, u=P_{\mathrm{ref}}^{\mathrm{WT}}, d=v_{\mathrm{w}}, z=\left[P_{\mathrm{g}}, F_{\mathrm{t}}, T_{\mathrm{s}}\right]^{\prime} . \theta$ is the pitch angle, $\omega_{\mathrm{r}}$ and $\omega_{\mathrm{f}}$ are the rotor speed and the filtered generator speed $\omega_{\mathrm{g}}, F_{\mathrm{t}}$ is the thrust force, $T_{\mathrm{r}}$ and $T_{\mathrm{s}}$ represent the rotor torque and the shaft torque, 


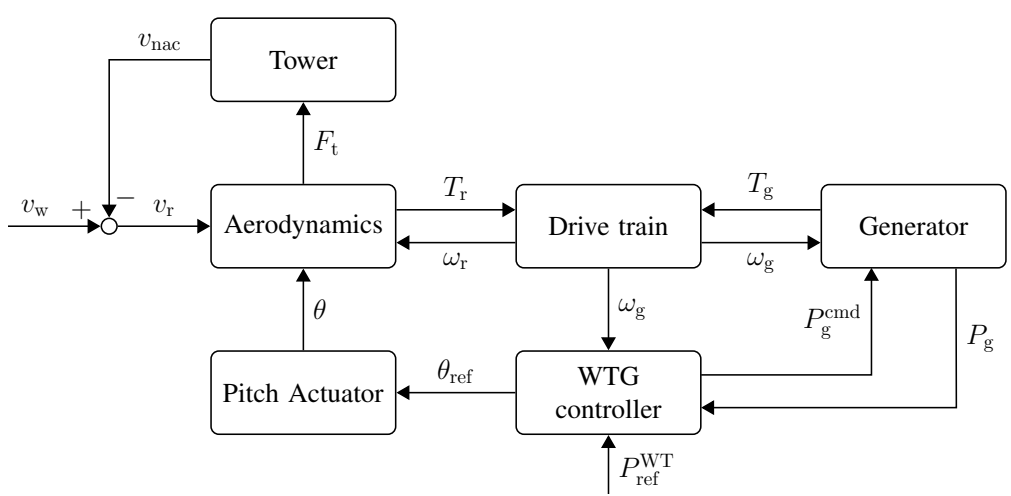

Figure 1. Single wind turbine system

respectively, $v_{\mathrm{w}}$ is the wind speed.

The state space matrices are,

$$
\begin{gathered}
A=\left[\begin{array}{ccc}
0 & -\frac{K_{\mathrm{P}}^{0} \eta_{\mathrm{g}}}{\tau_{g}} & \frac{K_{\mathrm{P}}^{0}-K_{\mathrm{I}}^{0} \tau_{g}}{\tau_{g}} \\
\frac{K_{\theta T_{\mathrm{r}}}}{J_{\mathrm{t}}} & \frac{K_{\mathrm{\omega}_{\mathrm{r}} T_{\mathrm{r}}}}{J_{\mathrm{t}}}+\frac{1}{J_{\mathrm{t}}} \frac{P_{\mathrm{ref}}^{0} \eta_{\mathrm{g}}}{\mu \omega_{\mathrm{g}}^{2}} & 0 \\
0 & \frac{\eta_{\mathrm{g}}}{\tau_{\mathrm{g}}} & -\frac{1}{\tau_{\mathrm{g}}}
\end{array}\right], B=\left[\begin{array}{c}
0 \\
-\frac{\eta_{\mathrm{g}}}{J_{\mathrm{t}} \mu \omega_{\mathrm{g}}^{0}} \\
0
\end{array}\right], E=\left[\begin{array}{c}
0 \\
\frac{K_{\mathrm{v}_{\mathrm{w}} T_{\mathrm{r}}}}{J_{\mathrm{t}}} \\
0
\end{array}\right], \\
C=\left[\begin{array}{ccc}
\frac{\eta_{\mathrm{g}}^{2} J_{\mathrm{g}} K_{\theta T_{\mathrm{r}}}}{J_{\mathrm{t}}} & \frac{\eta_{\mathrm{g}}^{2} J_{\mathrm{g}} K_{\mathrm{\omega}_{\mathrm{r}} T_{\mathrm{r}}}}{J_{\mathrm{t}}}-\frac{\eta_{\mathrm{g}}^{2} J_{\mathrm{r}} P_{\mathrm{ref}}^{0}}{J_{\mathrm{t}} \mu \omega_{\mathrm{g}}^{02}} & 0 \\
K_{\theta F_{\mathrm{t}}} & K_{\omega_{\mathrm{r}} F_{\mathrm{t}}} & 0
\end{array}\right], D=\left[\begin{array}{c}
\frac{1}{\mu \omega_{\mathrm{g}}^{0}} \\
0
\end{array}\right], F=\left[\begin{array}{c}
\frac{\eta_{\mathrm{g}}^{2} J_{\mathrm{g}} K_{v_{\mathrm{w}} T_{\mathrm{r}}}}{J_{\mathrm{t}}} \\
K_{v_{\mathrm{w}} F_{\mathrm{t}}}
\end{array}\right] .
\end{gathered}
$$

where $\eta_{\mathrm{g}}$ is the gear box ratio, $J_{\mathrm{t}}=J_{\mathrm{r}}+\eta_{\mathrm{g}}^{2} J_{\mathrm{g}}$ represents the equivalent inertia, $\tau_{\mathrm{g}}$ is the time constant of the generator speed filter, $K_{\mathrm{P}}^{0}, K_{\mathrm{I}}^{0}$ denote the proportional and integral gains of the pitch controller, $K_{\theta T_{\mathrm{r}}}, K_{\omega_{\mathrm{r}} T_{\mathrm{r}}}$, $K_{v_{\mathrm{w}} T_{\mathrm{r}}}, K_{\theta F_{\mathrm{t}}}, K_{\omega_{\mathrm{r}} F_{\mathrm{t}}}$ and $K_{v_{\mathrm{w}} F_{\mathrm{t}}}$ are the coefficients derived from the Taylor approximation of $T_{\mathrm{r}}$ and $F_{\mathrm{t}}$ at the operating point.

To guarantee the control performances within the whole range, the operating region is partitioned into several parts $\left(\chi_{i}\right)$ according to $P_{\mathrm{ref}}^{\mathrm{WT}}$ and $v_{\mathrm{w}}$. For each part, the wind turbine system is linearized at a typical operating point. A Piece-Wise Affine (PWA) model can be built,

$$
\begin{aligned}
x(k+1)= & A_{\mathrm{d}} x(k)+B_{\mathrm{d}} u(k)+E_{\mathrm{d}} d(k) \\
y(k)= & C_{\mathrm{d}} x(k)+D_{\mathrm{d}} u(k)+F_{\mathrm{d}} d(k) \\
& \text { if }\left[\begin{array}{c}
x(k) \\
u(k) \\
d(k)
\end{array}\right] \in \chi_{i}, \\
& x \in \mathcal{X}, u \in \mathcal{U}, d \in \mathcal{D} .
\end{aligned}
$$

$\mathcal{X}, \mathcal{U}$ and $\mathcal{D}$ are the feasible regions for $x, u$ and $d$, respectively, defined as follows, 


$$
\begin{gathered}
\mathcal{X}=\left\{\theta_{\min } \leq \theta \leq \theta_{\max }, \omega_{\mathrm{r} \_ \text {min }} \leq \omega_{\mathrm{r}} \leq \omega_{\mathrm{r} \_ \text {max }}, \eta_{\mathrm{g}} \omega_{\mathrm{r} \_\min } \leq \omega_{\mathrm{f}} \leq \eta_{\mathrm{g}} \omega_{\mathrm{r} \_\max }\right\}, \\
\mathcal{U}=\left\{P_{\min }^{\mathrm{WT}} \leq P_{\text {ref }}^{\mathrm{WT}} \leq P_{\max }^{\mathrm{WT}}\right\}, \\
\mathcal{D}=\left\{v_{\text {cut_in }} \leq v_{\mathrm{w}} \leq v_{\text {cut_out }}\right\},
\end{gathered}
$$

where $\theta_{\min }$ and $\theta_{\max }$ are the upper and lower limits of $\theta, \omega_{r_{-} \min }$ and $\omega_{\mathrm{r}_{-} \max }$ are the upper and lower limits of $\omega_{\mathrm{r}}, P_{\min }^{\mathrm{WT}}$ and $P_{\max }^{\mathrm{WT}}$ are the upper and lower limits of $P_{\text {ref }}^{\mathrm{WT}}, v_{\text {cut_in }}$ and $v_{\text {cut_out }}$ are the cut-in and cut-out wind speeds. Following the method introduced in [19], the discrete form of the state space matrices $\left(A_{\mathrm{d}}, B_{\mathrm{d}}, C_{\mathrm{d}}, D_{\mathrm{d}}\right.$, $\left.E_{\mathrm{d}}, F_{\mathrm{d}}\right)$ is formulated.

\subsection{Modeling of ESS unit}

A simple integrator is used to model the ESS unit and describe its State-Of-Charge (SOC) in discrete-time by,

$$
C^{\mathrm{ESS}}(k+1)=C^{\mathrm{ESS}}(k)-P_{\mathrm{ref}}^{\mathrm{ESS}}(k) \cdot t_{\mathrm{s}}-\eta_{\mathrm{loss}} \cdot C^{\mathrm{ESS}}(k)
$$

where $C^{\mathrm{ESS}}$ denotes SOC and $P_{\mathrm{ref}}^{\mathrm{ESS}}$ denotes the discharging power. A loss term modeled as $\eta_{\text {loss }} \cdot C^{\mathrm{ESS}}(k)$ is added to (3) and $\eta_{\text {loss }}$ indicates the loss coefficient [15].

The constraints of $C^{\mathrm{ESS}}, P_{\mathrm{ref}}^{\mathrm{ESS}}$ and $\Delta P_{\mathrm{ref}}^{\mathrm{ESS}}$ are

$$
\begin{array}{r}
P_{\text {ref }}^{\mathrm{ESS}} \in \mathcal{P}=\left\{-P_{\mathrm{lim}}^{\mathrm{ESS}} \leq P_{\mathrm{ref}}^{\mathrm{ESS}} \leq P_{\mathrm{lim}}^{\mathrm{ESS}}\right\}, \\
C^{\mathrm{ESS}} \in \mathcal{C}=\left\{C_{\mathrm{min}}^{\mathrm{ESS}} \leq C^{\mathrm{ESS}} \leq C_{\mathrm{max}}^{\mathrm{ESS}}\right\}, \\
\Delta P_{\mathrm{ref}}^{\mathrm{ESS}} \in \mathcal{R}=\left\{-\Delta P_{\mathrm{lim}}^{\mathrm{ESS}} \leq \Delta P_{\mathrm{ref}}^{\mathrm{ESS}} \leq \Delta P_{\mathrm{lim}}^{\mathrm{ESS}}\right\},
\end{array}
$$

where $P_{\mathrm{lim}}^{\mathrm{ESS}}$ indicates the power limit, $C_{\min }^{\mathrm{ESS}}$ and $C_{\max }^{\mathrm{ESS}}$ indicate the upper and lower limits of capacity, respectively and $\Delta P_{\text {lim }}^{\mathrm{ESS}}$ indicates the power rate limit. $\mathcal{P}, \mathcal{C}$ and $\mathcal{R}$ are the feasible regions of $P_{\mathrm{ref}}^{\mathrm{ESS}}, C^{\mathrm{ESS}}$ and $\Delta P_{\text {ref }}^{\mathrm{ESS}}$, respectively.

\section{D-MPC based wind farm control}

The wind field dynamics can be decoupled into two time scales [20]. The fast dynamic is related to the wind turbulence and gusts, which lead to the load increase. The slow dynamic is related to the mean wind speed which is used to represent the propagation of wind stream traveling through the wind farm. Due to the wake effects, there exists coherence among wind turbines. According to the wind field model and measurements of the wind farm, the mean wind speed of individual wind turbine can be estimated. 
Fig. 2 illustrates the hierarchical D-MPC control structure of a wind farm, which corresponds to the two timescale dynamics. For the high level control, $P_{\text {ref }}^{\mathrm{wfc}}$ is generated based on the TSO requirement and the available wind farm power. According to the wind field model and measurement, the mean wind speed of a certain period (several minutes) is estimated. Different approaches have been developed to distribute the mean power references for individual wind turbines $\overline{P_{\text {ref }}^{\mathrm{WT}_{i}}}$ [13]. In this study, the proportional distribution algorithm according to the available power of each turbine proposed in [1] is adopted,

$$
\overline{P_{\mathrm{ref}} \mathrm{WT}_{i}}=\frac{P_{\mathrm{avi}}^{\mathrm{WT}_{i}}}{\sum_{j=1}^{n_{\mathrm{t}}} P_{\mathrm{avi}}^{\mathrm{WT}_{j}}} P_{\mathrm{ref}}^{\mathrm{wfc}},
$$

where $P_{\mathrm{avi}}^{\mathrm{WT}_{i}}$ indicates the available wind power of the $i$ th turbine. The calculation of $P_{\mathrm{avi}}^{\mathrm{WT}_{i}}$ is expressed in (5). For simplicity, the index $i$ is neglected.

$$
P_{\text {avi }}^{\mathrm{WT}}=\left\{\begin{array}{ll}
0.5 \rho A_{\text {area }}\left(\overline{v_{\mathrm{w}}}\right)^{3} \cdot \xi & \text { if } v_{\text {cut_in }} \leq \overline{v_{\mathrm{w}}} \leq v_{\text {rated }} \\
P_{\text {rated }}^{\mathrm{WT}} & \text { if } v_{\text {rated }} \leq \overline{v_{\mathrm{w}}} \leq v_{\text {cut_out }}
\end{array},\right.
$$

where $\rho$ is the air density, $A_{\text {aera }}$ is the swept area of the wind turbine, $\xi$ is the wind turbine efficiency, $\overline{v_{\mathrm{w}}}$ is the mean wind speed, $v_{\text {rated }}$ is the rated wind speed, and $P_{\text {rated }}^{\mathrm{WT}}$ is the rated power. Conventionally, these mean power references are directly assigned to the wind turbines. The ESS is used to compensate the mismatch between the power reference $P_{\text {ref }}^{\mathrm{wfc}}$ and the actual power output $P_{\text {meas }}^{\mathrm{wfc}}$, the compensating power reference $P_{\mathrm{com}}^{\mathrm{ESS}}$ is calculated by $P_{\mathrm{com}}^{\mathrm{ESS}}=P_{\mathrm{ref}}^{\mathrm{wfc}}-P_{\text {meas }}^{\mathrm{wfc}}$. 


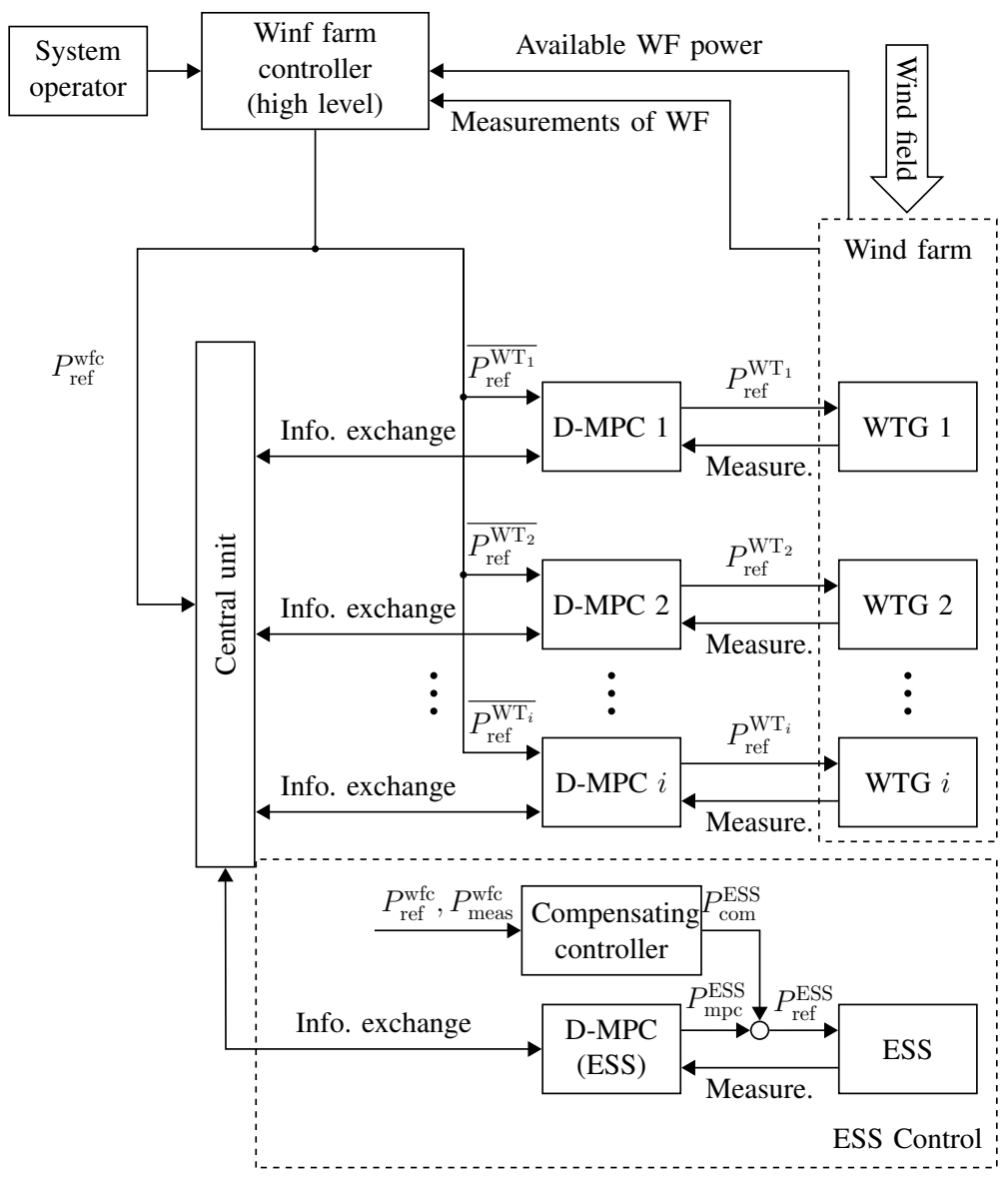

Figure 2. Control structure of wind farm based on D-MPC

In this study, these references are sent to the D-MPC controllers equipped at each wind turbine and the ESS unit. These controllers are considered as the low level wind farm control for dynamics. Through the mutual communication with the central unit, the iterations are executed until the global constraints are met. Subsequently, the reconfigured power references $P_{\text {ref }}^{\mathrm{WT}_{i}}$ and $P_{\text {ref }}^{\mathrm{ESS}}$ are assigned to the controllers of wind turbines and the ESS unit, respectively. Here, $P_{\text {ref }}^{\mathrm{ESS}}=P_{\mathrm{com}}^{\mathrm{ESS}}+P_{\mathrm{mpc}}^{\mathrm{ESS}}$.

\section{D-MPC using fast gradient method}

\subsection{MPC problem formulation}

In the high level control, the initial power reference for the $i$ th wind turbine $\overline{P_{\mathrm{ref}}^{\mathrm{WT}}}$ can be calculated according to (4). Accordingly, other steady state variables, e.g. the shaft torque $\overline{T_{\mathrm{S}}^{\mathrm{WT}_{i}}}$, can be decided. The ESS unit is not involved in this distribution. 
In the D-MPC, the prediction horizon is defined as $n_{\mathrm{p}}$ and $k$ indicates the prediction index. The decision variables $u$ include power references for wind turbines $\left(u^{\mathrm{WT}}\right)$ and ESS unit $\left(u^{\mathrm{ESS}}\right)$ over the prediction horizon. The wind turbine references are defined by $u^{\mathrm{WT}} \in \mathbb{R}^{\left(n_{\mathrm{p}} \cdot n_{\mathrm{t}}\right) \times 1}$ with $u^{\mathrm{WT}}=\left[u_{1}^{\mathrm{WT}}, \ldots, u_{n_{\mathrm{t}}}^{\mathrm{WT}^{\prime}}\right]^{\prime}$ and $u_{i}^{\mathrm{WT}}=\left[u_{i}^{\mathrm{WT}}(0), \ldots, u_{i}^{\mathrm{WT}}\left(n_{\mathrm{p}}-1\right)\right]^{\prime}$. Similarly, the ESS unit reference is defined by $u^{\mathrm{ESS}} \in \mathbb{R}^{n_{\mathrm{p}} \times 1}$, with $u^{\mathrm{ESS}}=\left[u^{\mathrm{ESS}}(0), \cdots, u^{\mathrm{ESS}}\left(n_{\mathrm{p}}-1\right)\right]^{\prime}$. Then, $u=\left[u^{\mathrm{WT}}, u^{\mathrm{ESS}}\right] \in \mathbb{R}^{\left[n_{\mathrm{p}} \cdot\left(n_{\mathrm{t}}+1\right)\right] \times 1}$.

The output variables $T_{\mathrm{s}}^{\mathrm{WT}_{i}}(k)$ and $F_{\mathrm{t}}^{\mathrm{WT}_{i}}(k)$ are defined by,

$$
\begin{aligned}
& T_{\mathrm{s}}^{\mathrm{WT}_{i}}(k)=S_{1} \cdot y_{i}(k), S_{1}=[1,0], \\
& F_{\mathrm{t}}^{\mathrm{WT}_{i}}(k)=S_{2} \cdot y_{i}(k), S_{2}=[0,1] .
\end{aligned}
$$

Then the MPC problem at time $t$ can be formulated as follows,

$$
\begin{aligned}
\min _{u^{\mathrm{WT}}, u^{\mathrm{ESS}}} \sum_{i=1}^{n_{\mathrm{t}}}\left(\sum_{k=0}^{n_{\mathrm{p}}}\left\|u_{i}^{\mathrm{WT}}(k)-\overline{P_{\mathrm{ref}}^{\mathrm{WT}}}\right\|_{Q_{P}}^{2}+\sum_{k=0}^{n_{\mathrm{p}}}\left\|S_{1} \cdot y_{i}(k)-\overline{T_{\mathrm{s}}^{\mathrm{WT}}}\right\|_{Q_{T}}^{2}\right. \\
\left.+\sum_{k=0}^{n_{\mathrm{p}}-1}\left\|\Delta\left(S_{2} \cdot y_{i}(k)\right)\right\|_{Q_{F}}^{2}\right)+\left\|C^{\mathrm{ESS}}-C_{\text {mid }}\right\|_{Q_{C}}^{2},
\end{aligned}
$$

subject to

$$
\begin{array}{r}
x_{i}(k+1)=A_{\mathrm{d}} x_{i}(k)+B_{\mathrm{d}} u_{i}^{\mathrm{WT}}(k)+E_{\mathrm{d}} d_{i}(k), \\
y_{i}(k)=C_{\mathrm{d}} x_{i}(k)+D_{\mathrm{d}} u_{i}^{\mathrm{WT}}(k)+F_{\mathrm{d}} d_{i}(k), \\
x_{i}(0)=x_{i}(t), \\
x_{i} \in \mathcal{X}_{i}, u_{i}^{\mathrm{WT}} \in \mathcal{U}_{i}, \\
C^{\mathrm{ESS}}(k+1)=C^{\mathrm{ESS}}(k)-\left(u^{\mathrm{ESS}}(k)+P_{\mathrm{com}}^{\mathrm{ESS}}\right) \cdot t_{\mathrm{s}}, \\
P_{\mathrm{com}}^{\mathrm{ESS}}(t)+u^{\mathrm{ESS}}(0)+\sum_{i=1}^{n_{\mathrm{t}}} u_{i}^{\mathrm{WT}}(0)=P_{\mathrm{ref}}^{\mathrm{wfc}}, \\
P_{\mathrm{com}}^{\mathrm{ESS}}(t)+u^{\mathrm{ESS}}(k) \in \mathcal{P}, C^{\mathrm{ESS}}(k) \in \mathcal{C}, \\
\Delta\left(P_{\mathrm{com}}^{\mathrm{ESS}}(t)+u^{\mathrm{ESS}}\right) \in \mathcal{R} .
\end{array}
$$

In (6), the second and third terms represent the penalty of the wind turbine load. The wind turbine tower is excited by $F_{\mathrm{t}}$ caused by the wind flowing on the rotor. The oscillatory transient leads to an undesired nodding of the tower, causing fatigue to the wind turbine. $T_{\mathrm{s}}$ is transferred through the gearbox which is vulnerable. The oscillatory transient of $T_{\mathrm{s}}$ will create micro cracks in the material and lead to the component failure.

As an approximate estimation of the wind turbine load, the quadratic representation for single wind turbine proposed in [12], [13] is used. The deviation of $T_{\mathrm{s}}$ from the steady state and the derivative of $F_{\mathrm{t}}$ are penalized to reduce the wind turbine load. In the fourth term, in order to facilitate the long term and stable operation of the ESS unit, its SOC is limited within the range of close to the medium SOC level $C_{\text {mid }}$ as much as possible [21]. $Q_{P}, Q_{T}, Q_{F}$ 
and $Q_{C}$ are the weighting factors.

For the constraints (7)-(13), $\mathcal{X}_{i}$ and $\mathcal{U}_{i}$ are the local state and control input constraint sets, respectively. As the optimization variables $u$, the first values are taken as the control inputs for each turbine and ESS unit, i.e. $P_{\mathrm{ref}}^{\mathrm{WT}}(t)=u^{\mathrm{WT}}(0)$ and $P_{\mathrm{mpc}}^{\mathrm{ESS}}(t)=u^{\mathrm{ESS}}(0)$. The control inputs are coupled whose sum equals to $P_{\mathrm{ref}}^{\mathrm{wfc}}$ (see (11)).

By substituting (11) into (12),

$$
P_{\mathrm{ref}}^{\mathrm{wfc}}-P_{\mathrm{lim}}^{\mathrm{ESS}} \leq \sum_{i=1}^{n_{\mathrm{t}}} u_{i}^{\mathrm{WT}}(0) \leq P_{\mathrm{ref}}^{\mathrm{wfc}}+P_{\lim }^{\mathrm{ESS}}
$$

If there is no ESS unit, (14) is changed into,

$$
P_{\mathrm{ref}}^{\mathrm{wfc}} \leq \sum_{i=1}^{n_{\mathrm{t}}} u_{i}^{\mathrm{WT}}(0) \leq P_{\mathrm{ref}}^{\mathrm{wfc}}
$$

Obviously, the control inputs in (14) have more regulation flexibility, compared to (15). Accordingly, a better load minimization performance can be expected with the ESS unit. To what extent that the load minimization can be improved is dependent on the technical features of the ESS unit, including response time, power and energy ratings, etc.

\subsection{Parallel generalized fast dual method}

The parallel generalized fast dual method is used to solve the MPC problem formulated in Section 4.1.

4.2.1. Primal problem. The MPC problem can be reformulated as the following standard Quadratic Programming (QP) problem with Hessian matrix $H_{i} \in \mathbb{R}^{n_{\mathrm{p}} \times n_{\mathrm{p}}}$ (positive definite) and coefficient vector $g_{i} \in \mathbb{R}^{n_{\mathrm{p}} \times 1}$,

$$
\min _{u} \Phi=\sum_{i=1}^{n_{\mathrm{t}}+1} \Phi_{i}\left(u_{i}\right)=\sum_{i=1}^{n_{\mathrm{t}}+1}\left(\frac{1}{2} u_{i}^{\prime} H_{i} u_{i}+g_{i}^{\prime} u_{i}\right)
$$

subject to

$$
\begin{gathered}
G u=b \\
u \in \mathcal{U} .
\end{gathered}
$$

According to the method introduced in [19], $H_{i}$ can be calculated by (7), (10) and $n_{\mathrm{p}} . g_{i}$ can be derived according

to (7), (10), $n_{\mathrm{p}}$ and $\overline{P_{\mathrm{ref}} \mathrm{WT}^{2}}$. The coupling of the control inputs described in (11) can be rewritten as the equality constraint (17). Accordingly, $G$ and $b$ can be expressed by,

$$
\begin{aligned}
& G=\left[G_{1}, \cdots, G_{n_{\mathrm{t}}+1}\right], G_{i}=[1,0, \cdots, 0], G_{i} \in \mathbb{R}^{1 \times n_{\mathrm{p}}}, \\
& b=P_{\mathrm{ref}}^{\mathrm{wfc}} .
\end{aligned}
$$


4.2.2. Properties of dual problem. The key properties of the dual problem proved in [17] are briefly described, which are the theoretical foundation of the distribution optimization algorithm.

Property: Assume that function $\Phi$ and its local function $\Phi_{i}$ are strongly convex, the dual functions $d$ and $d_{i}$ are concave, differentiable and satisfies the following inequalities for every dual variables $\lambda_{1}, \lambda_{2}$, $\mathbf{L}$ with $\mathbf{L} \succeq G H^{-1} G^{\prime}$ and $\mathbf{L}_{i}$ with $\mathbf{L}_{i} \succeq G_{i} H_{i}^{-1} G_{i}^{\prime}$.

$$
\begin{gathered}
d\left(\lambda_{1}\right) \geq d\left(\lambda_{2}\right)+\nabla d\left(\lambda_{2}\right)\left(\lambda_{1}-\lambda_{2}\right)-\frac{1}{2}\left\|\lambda_{1}-\lambda_{2}\right\|_{\mathbf{L}}^{2} \\
d_{i}\left(\lambda_{1}\right) \geq d_{i}\left(\lambda_{2}\right)+\nabla d_{i}\left(\lambda_{2}\right)\left(\lambda_{1}-\lambda_{2}\right)-\frac{1}{2}\left\|\lambda_{1}-\lambda_{2}\right\|_{\mathbf{L}_{i}}^{2}
\end{gathered}
$$

This property offers a tight quadratic lower bound to the dual function. The obtained bound can be further proved to be the best obtained bound. Consequently, a more accurate approximation of the dual function can be derived and the convergence rate can be improved. Based on this property, a generalized parallel optimization algorithm was proposed in [17] for D-MPC.

4.2.3. Distributed algorithm. The parallel fast dual gradient method for the wind farm control is described in this part. In order to limit the online computation time, a fixed iteration number $k_{\max }$ is predefined as the stopping criterion.

\section{Wind farm control with parallel fast dual gradient method}

Require: Introduce the dual variables $\lambda, \eta$ and $\phi$. Initial guesses $\lambda^{[1]}=\eta^{[0]}, \phi^{[1]}=1$.

for: $k=1, \ldots, k_{\max }$, do

1) Send $\lambda^{[k]}$ to all wind turbines and ESS unit $i \in\left\{1, \ldots n_{\mathrm{t}}+1\right\}$ through communication (Central Unit $\Rightarrow$ D-MPC).

2) Update and solve the local optimization with augmented cost function in individual D-MPCs equipped in the wind turbines and ESS unit:

$u_{i}^{[k]}=\arg \min _{u_{i}}\left\{\Phi_{i}+u_{i}^{\prime} G_{i}^{\prime} \lambda^{[k]}\right\}$.

3) Update $\mathbf{L}_{i}^{-1}$ in D-MPC of the wind turbine, once the operating region of the wind turbine changes.

4) Receive $u_{i}^{[k]}$ from the wind turbines and the ESS unit and form $u^{[k]}=\left(u_{1}^{[k]}, \ldots, u_{n_{t}+1}^{[k]}\right)$ (D-MPC $\Rightarrow$ Central Unit). 
5) Receive the updated $\mathbf{L}_{i}^{-1}$ (D-MPC $\Rightarrow$ Central Unit) and then update $\mathbf{L}^{-1}$ according to $\mathbf{L}_{i}^{-1}$ in Central Unit:

$$
\begin{aligned}
& \eta^{[k]}=\lambda^{[k]}+\mathbf{L}^{-1}\left(G u^{[k]}-b\right) \\
& \phi^{[k+1]}=\frac{1+\sqrt{1+4\left(\phi^{[k]}\right)^{2}}}{2} \\
& \lambda^{[k+1]}=\eta^{[k]}+\left(\frac{\phi^{[k]}-1}{\phi^{[k+1]}}\right)\left(\eta^{[k]}-\eta^{[k-1]}\right)
\end{aligned}
$$

end for

Proposition: As proved in [17], if the property described in Section 4.2.2 holds and $\mathbf{L} \succeq G H^{-1} G^{\prime}$, the convergence rate of the algorithm is improved from $\mathcal{O}(1 / k)$ to $\mathcal{O}\left(1 / k^{2}\right)$ with negligible increase in iteration complexity.

$\mathbf{L}=G H^{-1} G^{\prime}$ has the tightest upper bounds and is adopted. $\mathbf{L}^{-1}$ can be calculated by,

$$
\mathbf{L}^{-1}=\sum_{i=1}^{n_{\mathrm{t}}+1} \mathbf{L}_{i}^{-1}=\sum_{i=1}^{n_{\mathrm{t}}+1}\left(G_{i} H_{i}^{-1} G_{i}\right)^{-1}
$$

For the wind turbines, the linearized model parameters change with the operating region. Accordingly, $H_{i}$ is timevariant which further leads to the variation of $\mathbf{L}_{i}^{-1}$. To reduce the online computation complexity, the variables involved in the computation, including $H_{i}$ and $\mathbf{L}_{i}^{-1}$, can be pre-computed offline and stored according to the operation regions. For the ESS unit, the model parameters are invariant and its $H_{i}$ is fixed.

Most computation tasks are distributed to the local D-MPCs, the computation burden of Central Unit only consists of the calculation of $\mathbf{L}^{-1}$ which is a simple addition of the individual $\mathbf{L}_{i}^{-1}$ and the dual variable updates during iterations. Furthermore, the improved convergence rate leads to the reduced iteration number. Therefore, the communication burden between D-MPCs and the Central Unit has been largely reduced.

For the local D-MPCs, the computation task consists of the formulation of the optimization problem and the solution of the problem. Due to the updates of $H_{i}$ and $g_{i}$, the optimization problem should be reformulated for each time step. As described above, $H_{i}$ has been pre-computed and stored. The search of the corresponding $H_{i}$ is much faster than the sampling time $t_{\mathrm{s}} . g_{i}$ is dependent on $\overline{P_{\text {ref }}^{\mathrm{WT}_{i}}}$, which is time-variant. Since $g_{i} \in \mathbb{R}^{n_{\mathrm{p}} \times 1}$, the low-rank matrix calculation is quite fast. Besides, the computation of solving the formulated low-rank QP problem is also fast (in milliseconds). Therefore, as long as the iteration number is not very large, the computation burden of the local D-MPCs is not heavy. 


\section{Case studies}

The developed wind farm controller was tested in a wind farm with $10 \times 5 \mathrm{MW}$ wind turbines $\left(n_{\mathrm{t}}=10\right)$ and a $500 \mathrm{~kW} / 3 \mathrm{kWh}$ ESS (e.g. Super-capacitor) with power rate limit $\Delta P_{\mathrm{ref}}^{\mathrm{ESS}}=300 \mathrm{~kW} / \mathrm{s}$. The mean wind speed of each wind turbine $(10 \mathrm{~min})$ is assumed to be known. The wind field of the wind farm is generated from the built-in wind model in SimWindFarm, which is a Matlab toolbox for dyanmic wind farm model, simulation and control [22]. The correlations among upstream-downstream wind and wake effects are taken into account in the wind model. The sampling time of the wind farm control was set as $t_{\mathrm{s}}=1 \mathrm{~s}$. The prediction horizon was set as $n_{\mathrm{p}}=10$. The real-time wind speed can be estimated and the value for the prediction horizon is based on persistence assumption.

\subsection{Convergence with the fast gradient method}

As described in Section 4.2.3, the proposition is met, if $\mathbf{L} \succeq G H^{-1} G^{\prime}$. However, the value of $\mathbf{L}$ can affect the convergence. The convergences of the fast dual gradient method with different $\mathbf{L}$ were compared in Fig. 3, where the vertical axis indicates the deviation to the constraints (see (11)). Obviously, when $\mathbf{L} \succeq G H^{-1} G^{\prime}$, the convergence rate is higher $\left(\mathbf{L}_{1}, \mathbf{L}_{2}>\mathbf{L}_{3}\right)$. Especially when $\mathbf{L}=G H^{-1} G^{\prime}$, it has the tightest upper bounds and the convergence is fastest. It can be observed that a good performance of the D-MPC is guaranteed by about 5 iterations. Therefore, the maximum iteration number $k_{\max }$ is set as 5 in the following simulations.

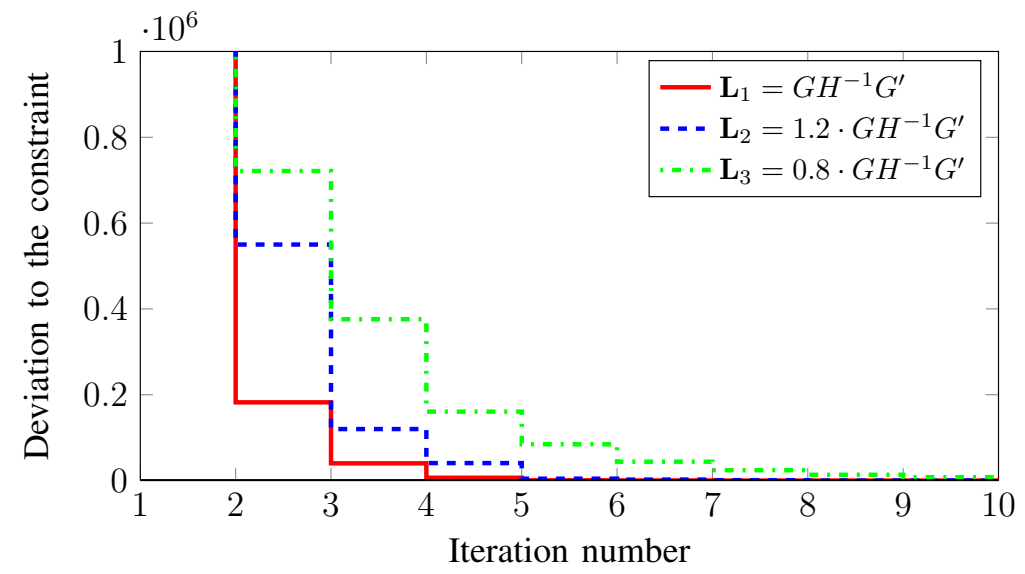

Figure 3. Convergence comparison with different $\mathbf{L}$

\subsection{Wind farm operation with the developed D-MPC}

In this section, the operation of the wind farm was simulated and studied under both high and low wind conditions. $P_{\text {ref }}^{\mathrm{wfc}}$ is decided according to the TSO requirement and the available wind farm power. For the sake of simplification, 
$P_{\text {ref }}^{\mathrm{wfc}}$ is assumed to be fixed during the simulation. Accordingly, for the high wind condition, $P_{\text {ref }}^{\mathrm{wfc}}=40 \mathrm{MW} . \overline{v_{\mathrm{w}}}$ of individual wind turbines are above the rated wind speed $(11.4 \mathrm{~m} / \mathrm{s})$, listed in Tables 2 and 4 . Therefore, the available power for all the turbines are the same (5 MW). In the high level wind farm control, according to (4), $\overline{P_{\mathrm{ref}}^{\mathrm{WF}}}=\frac{P_{\mathrm{ref}}^{\mathrm{wfc}}}{n_{\mathrm{t}}}=4 \mathrm{MW}$. For the low wind condition, the same wind profile was shifted downward. $\overline{v_{\mathrm{w}}}$ of individual wind turbines are below the rated wind speed, listed in Table 3 and 5. $P_{\text {ref }}^{\text {wfc }}$ is defined as $12 \mathrm{MW}$. Unlike the high wind speed condition, the available power for all the wind turbines are different which leads to the different distribution factors of the power references for all the turbines. The simulation time was set as $300 \mathrm{~s}$. The weighting factors in (6) were defined: $Q_{P}=1, Q_{T}=30, Q_{F}=1, Q_{C}=1$. As suggested in [12], $Q_{F}$ should be kept small to avoid violent control and shaft load increase.

The objectives of the wind farm controller include power reference tracking, wind turbine load minimization and optimal operation of the ESS unit. Since the mismatch between $P_{\text {ref }}^{\text {wfc }}$ and $P_{\text {meas }}^{\text {wfc }}$ can be compensated by ESS through the additional power command $P_{\text {com }}^{\mathrm{ESS}}$, the power reference tracking performance is not illustrated. In the following subsections, the results related to the latter two control objectives are shown.

5.2.1. Wind turbine load alleviation. The shaft and thrust-induced loads are quantified by the standard deviation $\sigma\left(T_{\mathrm{s}}\right)$ and $\sigma\left(\Delta F_{\mathrm{t}}\right)$, respectively. The performances of all wind turbines are similar. Therefore, a single wind turbine (WT 10) was selected for illustration. The wind speed variations under both high and low wind conditions are shown in Fig. 4, which covers from $12.1 \mathrm{~m} / \mathrm{s}$ to $16.8 \mathrm{~m} / \mathrm{s}$ for the high wind condition and from $6.2 \mathrm{~m} / \mathrm{s}$ to $10.8 \mathrm{~m} / \mathrm{s}$ for the low wind condition. Case study scenarios are listed in Table 1.

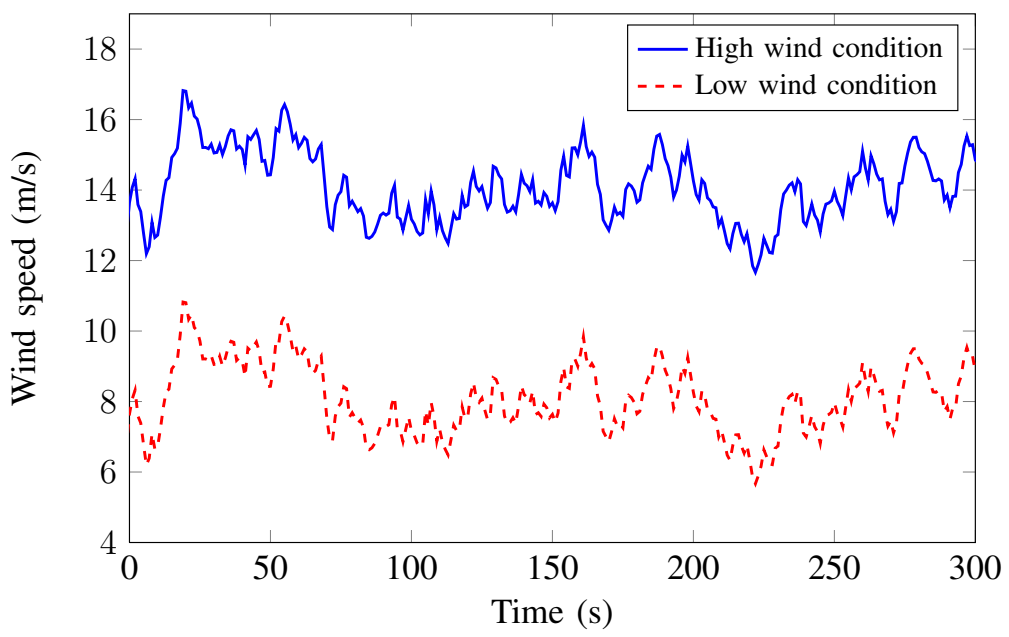

Figure 4. Wind speed variation of WT 10 
Table 1. Case scenario definition

\begin{tabular}{l|l|l}
\hline Scenario & Wind farm controller & Description \\
\hline \hline Scenario 1 & Conventional Control without ESS & $\begin{array}{l}\text { No ESS. } P_{\text {ref }}^{\mathrm{WF}_{i}} \text { is calculated based on } \\
\text { the proportional distribution algorithm. }\end{array}$ \\
\hline Scenario 2 & D-MPC without ESS & $\begin{array}{l}\text { No ESS. } P_{\text {ref }}^{\mathrm{WF}_{i}} \text { is calculated based on } \\
\text { the D-MPC algorithm. }\end{array}$ \\
\hline Scenario 3 & C-MPC with ESS & $\begin{array}{l}\text { With ESS. } P_{\text {ref }}^{\mathrm{WF}_{i}} \text { and } P_{\text {ref }}^{\mathrm{ESS}} \text { are calcu- } \\
\text { lated based on the C-MPC algorithm. }\end{array}$ \\
\hline Scenario 4 & D-MPC with ESS & $\begin{array}{l}\text { With ESS. } P_{\text {ref }}^{\mathrm{WF}_{i}} \text { and } P_{\mathrm{ref}}^{\mathrm{ESS}} \text { are calcu- } \\
\text { lated based on the D-MPC algorithm. }\end{array}$ \\
\hline
\end{tabular}

The waveforms of $T_{\mathrm{s}}$ and $F_{\mathrm{t}}$ of WT 10 with different controllers are shown in Fig. 5-6. The standard deviation of $T_{\mathrm{s}}$ and $\Delta F_{\mathrm{t}}$ of all the wind turbines are listed in Tables 2-5.

(a)

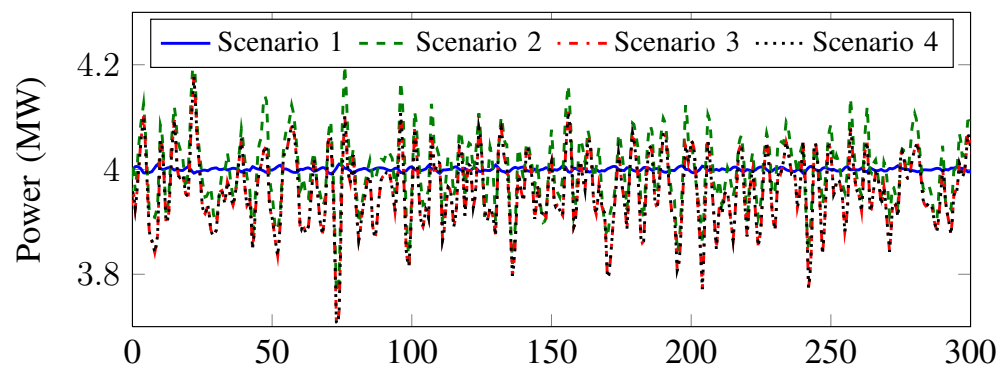

(b)

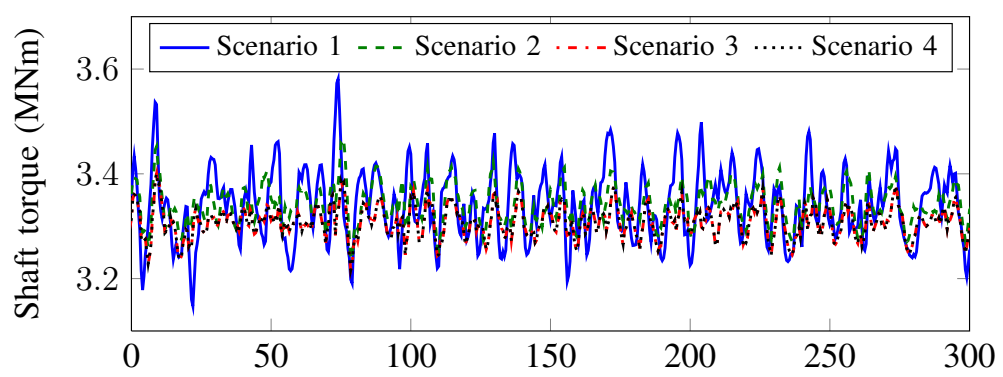

(c)

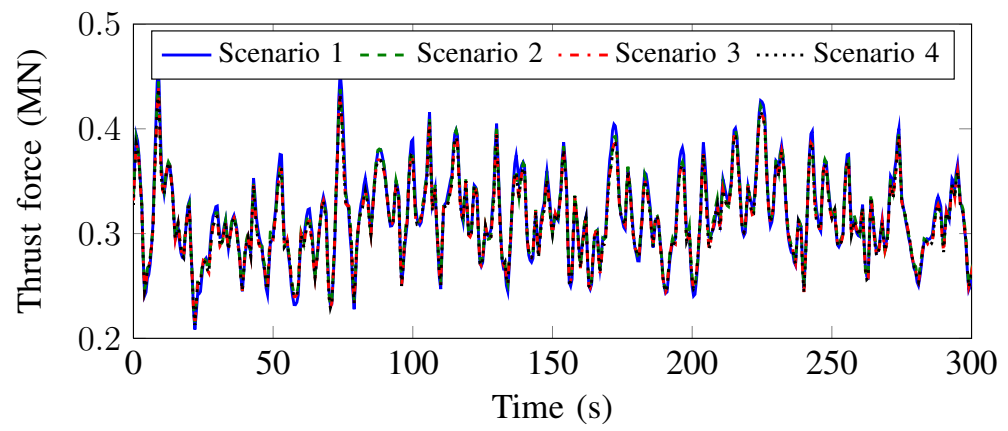

Figure 5. Simulation results of WT 10 under high wind condition 
(a)

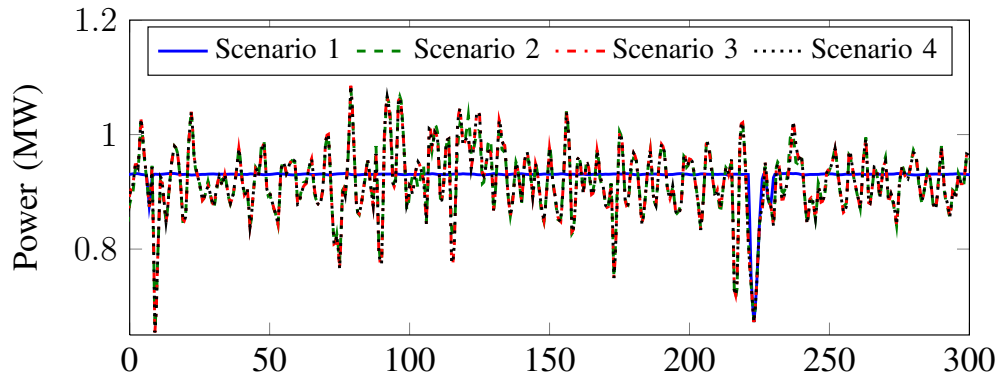

(b)

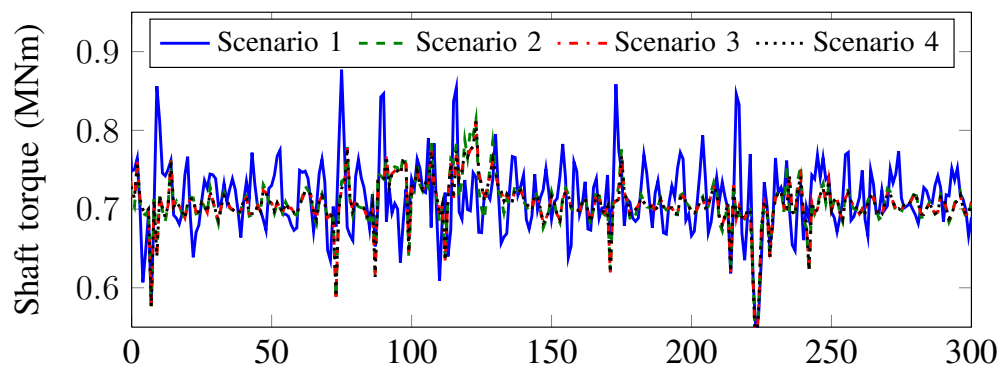

(c)

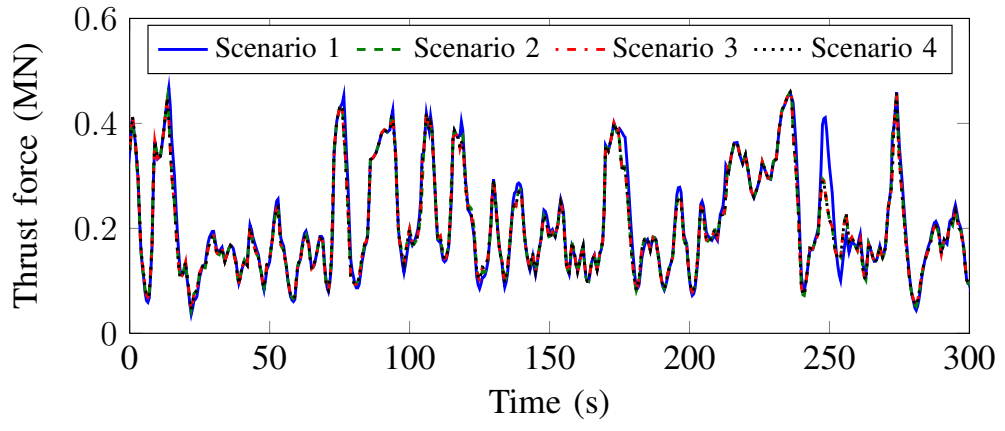

Figure 6. Simulation results of WT 10 under low wind condition

In Fig. 5(a) and Fig. 6(a), it is shown that the power references of Scenarios 2-4 vary following the wind speed under both high and low wind conditions. It should be noticed that under the low wind condition, the wind speed of a wind turbine may not be high enough to support its power reference. In that case, the output power of the wind turbine is the maximum available power, as illustrated in Fig. 6(a) (the power dip between $t=220 \mathrm{~s}$ and $t=235 \mathrm{~s}$ ). Compared with Scenario 1, the deviation of the shaft torque is significantly reduced (Fig. 5(b) and Fig. 6(b)). Due to the small weighting factor $Q_{F}$, the alleviation of the thrust force is not significant (Fig. 5(c) and Fig. 6(c)). The control performances of Scenario 3 and Scenario 4 are almost identical while there exist differences between Scenario 2 and Scenarios 3-4. 
Table 2. Standard Deviation $\sigma\left(T_{\mathrm{s}}\right)$ in $0.01 \mathrm{MNm}$ (High Wind Speed)

\begin{tabular}{c|c|c|c|c|c}
\hline Turbine & $v_{\text {avr }}(\mathrm{m} / \mathrm{s})$ & Scenario 1 & Scenario 2 & Scenario 3 & Scenario 4 \\
\hline \hline WT 01 & 15.05 & 6.26 & $2.83(-54.79 \%)$ & $2.02(-67.73 \%)$ & $2.02(-67.73 \%)$ \\
\hline WT 02 & 15.11 & 6.23 & $2.98(-52.17 \%)$ & $2.15(-65.49 \%)$ & $2.15(-65.49 \%)$ \\
\hline WT 03 & 14.81 & 6.10 & $2.82(-53.77 \%)$ & $1.92(-68.52 \%)$ & $1.92(-68.52 \%)$ \\
\hline WT 04 & 14.81 & 6.18 & $3.15(-49.03 \%)$ & $2.33(-62.30 \%)$ & $2.33(-62.30 \%)$ \\
\hline WT 05 & 14.94 & 6.89 & $3.31(-51.96 \%)$ & $2.33(-66.18 \%)$ & $2.33(-66.18 \%)$ \\
\hline WT 06 & 15.10 & 5.70 & $2.85(-50.00 \%)$ & $2.05(-64.04 \%)$ & $2.05(-64.04 \%)$ \\
\hline WT 07 & 14.24 & 6.01 & $3.13(-47.92 \%)$ & $2.77(-53.91 \%)$ & $2.77(-53.91 \%)$ \\
\hline WT 08 & 14.54 & 6.48 & $3.18(-50.93 \%)$ & $2.52(-61.11 \%)$ & $2.52(-61.11 \%)$ \\
\hline WT 09 & 15.21 & 6.63 & $3.34(-49.62 \%)$ & $2.27(-65.76 \%)$ & $2.27(-65.76 \%)$ \\
\hline WT 10 & 14.09 & 6.29 & $3.47(-44.83 \%)$ & $2.88(-54.21 \%)$ & $2.88(-54.21 \%)$ \\
\hline
\end{tabular}

Table 3. Standard Deviation $\sigma\left(T_{\mathrm{s}}\right)$ in $0.01 \mathrm{MNm}$ (Low Wind Speed)

\begin{tabular}{c|c|c|c|c|c}
\hline Turbine & $v_{\text {avr }}(\mathrm{m} / \mathrm{s})$ & Scenario 1 & Scenario 2 & Scenario 3 & Scenario 4 \\
\hline \hline WT 01 & 9.05 & 6.04 & $4.75(-21.36 \%)$ & $4.45(-26.32 \%)$ & $4.45(-26.32 \%)$ \\
\hline WT 02 & 9.11 & 4.10 & $3.46(-15.61 \%)$ & $3.37(-17.80 \%)$ & $3.37(-17.80 \%)$ \\
\hline WT 03 & 8.81 & 3.74 & $2.87(-23.26 \%)$ & $2.62(-29.95 \%)$ & $2.62(-29.95 \%)$ \\
\hline WT 04 & 8.81 & 4.52 & $3.40(-24.78 \%)$ & $3.33(-26.33 \%)$ & $3.33(-26.33 \%)$ \\
\hline WT 05 & 8.94 & 4.69 & $2.97(-36.67 \%)$ & $2.77(-40.94 \%)$ & $2.77(-40.94 \%)$ \\
\hline WT 06 & 9.10 & 3.69 & $2.78(-24.66 \%)$ & $2.75(-25.47 \%)$ & $2.75(-25.47 \%)$ \\
\hline WT 07 & 8.24 & 4.25 & $2.83(-33.41 \%)$ & $2.59(-39.06 \%)$ & $2.59(-39.06 \%)$ \\
\hline WT 08 & 8.54 & 4.04 & $2.83(-29.95 \%)$ & $2.63(-34.90 \%)$ & $2.63(-34.90 \%)$ \\
\hline WT 09 & 9.21 & 3.97 & $2.80(-29.47 \%)$ & $2.42(-39.04 \%)$ & $2.42(-39.04 \%)$ \\
\hline WT 10 & 8.09 & 4.58 & $3.19(-30.35 \%)$ & $3.02(-34.06 \%)$ & $3.02(-34.06 \%)$ \\
\hline
\end{tabular}

According to the results in Table 2 and Table 3, $\sigma\left(T_{\mathrm{s}}\right)$ is reduced largely in Scenario 2, compared with Scenario 1. By taking $\sigma\left(T_{\mathrm{s}}\right)$ in Scenario 1 as the reference, the reduction of Scenario 2 ranges from $44.83 \%$ to $54.79 \%$ under the high wind condition (Table 2) and $15.61 \%$ to $36.67 \%$ under the low wind condition (Table 3). Based on this, the additional ESS further increases the reduction values of each wind turbine, which range from $53.91 \%$ to $68.52 \%$ in Scenario 3 and 4 under the high wind condition (Table 2) and $17.80 \%$ to $40.94 \%$ under the low wind condition (Table 3). These results verify the expectation made in Section 4.1. 
Table 4. Standard Deviation $\sigma\left(\Delta F_{\mathrm{t}}\right)$ in $0.01 \mathrm{MN}$ (High Wind Speed)

\begin{tabular}{c|c|c|c|c|c}
\hline Turbine & $v_{\text {avr }}(\mathrm{m} / \mathrm{s})$ & Scenario 1 & Scenario 2 & Scenario 3 & Scenario 4 \\
\hline \hline WT 01 & 15.05 & 1.68 & $1.64(-2.38 \%)$ & $1.63(-2.98 \%)$ & $1.63(-2.98 \%)$ \\
\hline WT 02 & 15.11 & 1.65 & $1.60(-3.03 \%)$ & $1.59(-3.64 \%)$ & $1.59(-3.64 \%)$ \\
\hline WT 03 & 14.81 & 1.75 & $1.70(-2.86 \%)$ & $1.70(-2.86 \%)$ & $1.70(-2.86 \%)$ \\
\hline WT 04 & 14.81 & 1.69 & $1.63(-3.55 \%)$ & $1.61(-4.73 \%)$ & $1.61(-4.73 \%)$ \\
\hline WT 05 & 14.94 & 1.96 & $1.90(-3.06 \%)$ & $1.89(-3.57 \%)$ & $1.89(-3.57 \%)$ \\
\hline WT 06 & 15.10 & 1.59 & $1.57(-1.26 \%)$ & $1.55(-2.52 \%)$ & $1.55(-2.52 \%)$ \\
\hline WT 07 & 14.24 & 1.82 & $1.76(-3.30 \%)$ & $1.75(-3.85 \%)$ & $1.75(-3.85 \%)$ \\
\hline WT 08 & 14.54 & 1.75 & $1.68(-4.00 \%)$ & $1.68(-4.00 \%)$ & $1.68(-4.00 \%)$ \\
\hline WT 09 & 15.21 & 1.75 & $1.69(-3.43 \%)$ & $1.69(-3.43 \%)$ & $1.69(-3.43 \%)$ \\
\hline WT 10 & 14.09 & 1.82 & $1.76(-3.30 \%)$ & $1.74(-4.40 \%)$ & $1.74(-4.40 \%)$ \\
\hline
\end{tabular}

Table 5. Standard Deviation $\sigma\left(\Delta F_{\mathrm{t}}\right)$ in $0.01 \mathrm{MN}$ (Low Wind Speed)

\begin{tabular}{c|c|c|c|c|c}
\hline Turbine & $v_{\text {avr }}(\mathrm{m} / \mathrm{s})$ & Scenario 1 & Scenario 2 & Scenario 3 & Scenario 4 \\
\hline \hline WT 01 & 9.05 & 2.14 & $2.06(-3.74 \%)$ & $2.05(-4.21 \%)$ & $2.05(-4.21 \%)$ \\
\hline WT 02 & 9.11 & 2.35 & $2.30(-2.13 \%)$ & $2.30(-2.13 \%)$ & $2.30(-2.13 \%)$ \\
\hline WT 03 & 8.81 & 2.47 & $2.44(-1.21 \%)$ & $2.44(-1.21 \%)$ & $2.44(-1.21 \%)$ \\
\hline WT 04 & 8.81 & 2.05 & $2.02(-1.46 \%)$ & $2.00(-2.44 \%)$ & $2.00(-2.44 \%)$ \\
\hline WT 05 & 8.94 & 2.67 & $2.64(-1.12 \%)$ & $2.61(-2.25 \%)$ & $2.61(-2.25 \%)$ \\
\hline WT 06 & 9.10 & 2.01 & $1.91(-4.98 \%)$ & $1.96(-2.49 \%)$ & $1.96(-2.49 \%)$ \\
\hline WT 07 & 8.24 & 2.66 & $2.49(-6.39 \%)$ & $2.48(-6.77 \%)$ & $2.48(-6.77 \%)$ \\
\hline WT 08 & 8.54 & 2.45 & $2.33(-4.90 \%)$ & $2.32(-5.31 \%)$ & $2.32(-5.31 \%)$ \\
\hline WT 09 & 9.21 & 2.66 & $2.59(-2.63 \%)$ & $2.58(-3.01 \%)$ & $2.58(-3.01 \%)$ \\
\hline WT 10 & 8.09 & 2.52 & $2.37(-5.95 \%)$ & $2.36(-6.35 \%)$ & $2.36(-6.35 \%)$ \\
\hline
\end{tabular}

According to the results in Table 4 and Table 5, $\sigma\left(\Delta F_{\mathrm{t}}\right)$ of each wind turbine is also reduced to some extent in Scenario 2. By taking $\sigma\left(\Delta F_{\mathrm{t}}\right)$ in Scenario 1 as the reference, the reduction ranges from $1.26 \%$ to $4.00 \%$ under the high wind condition (Table 4) and $1.12 \%$ to $6.39 \%$ under the low wind condition (Table 5). The additional ESS further increases the reduction under the high wind condition, which range from $2.28 \%$ to $4.64 \%$ in Scenario 3 and 4 (Table 4). For the low wind case, the reduction of most turbines is further increased by the additional ESS, except WT06. However, from the whole wind farm point of view, the thrust force induced loads experienced by all wind turbines are alleviated. The reduction ranges from $1.21 \%$ to $6.77 \%$ in Scenario 3 and 4 (Table 5).

From Table 2-5, it can also be observed that $\sigma\left(T_{\mathrm{s}}\right)$ and $\sigma\left(\Delta F_{\mathrm{t}}\right)$ of Scenario 3 are the same as these of Scenario 4, which proves that the D-MPC has the same control performance as the C-MPC.

5.2.2. Operation of the ESS unit. In this paper, the medium $\mathrm{SOC}$ level is set as $C_{\mathrm{mid}}=50 \%$. The $\mathrm{SOC}$ variations of the ESS unit under both high and low wind conditions are illustrated in Fig. 7(a) and Fig. 7(b), respectively. With the developed D-MPC controller, the SOC can be observed to operate around the $C_{\text {mid }}$, which is within $25 \%$ to $65 \%$. 
(a)

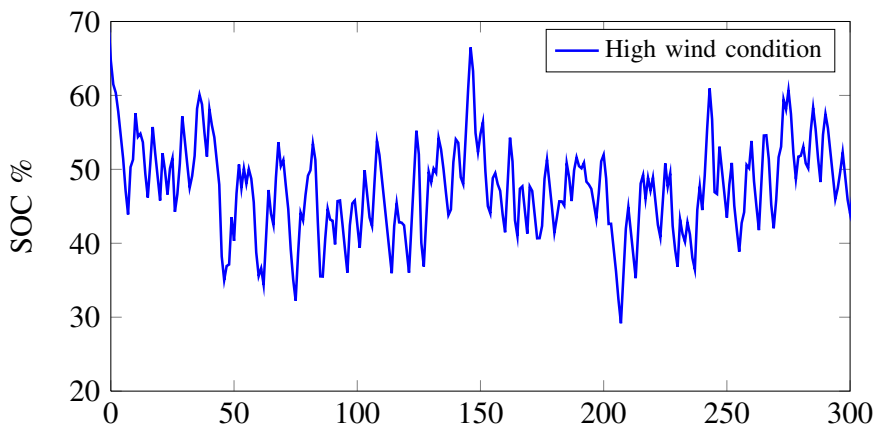

(b)

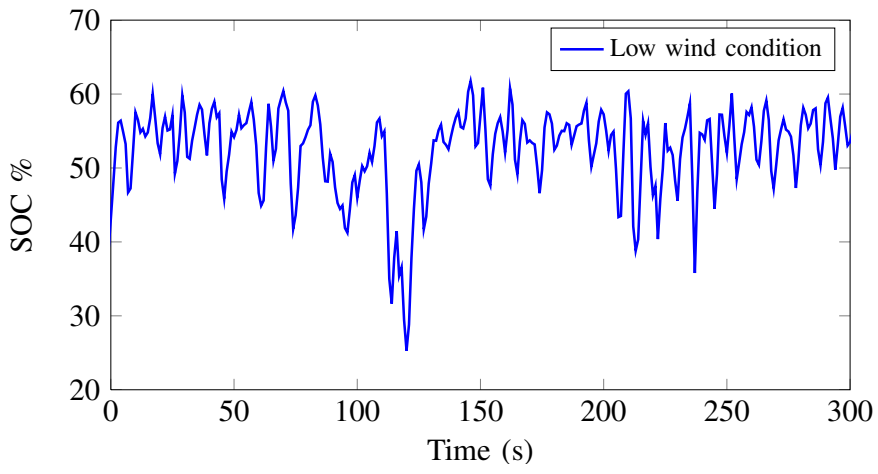

Figure 7. SOC of the ESS unit

\section{Conclusion}

With a fast and short-term ESS unit in the wind farm, it can not only compensate the mismatch between the required power by TSOs and actual power output, but also contribute to the minimization of the wind turbine load by coordination with wind turbines using the D-MPC. Compared to the conventional wind farm control without ESS, the wind turbine load is largely reduced, which is verified by the case study. In this paper, only a single ESS unit is considered. However, the developed algorithm can also be extended for multiple ESS units cases.

The D-MPC algorithm based on the fast dual gradient method was developed to solve the multi-objective control problem of the wind farm with an ESS. Compared with the C-MPC, most of the computation tasks are distributed to the local D-MPCs equipped at the wind turbines and the ESS unit. Accordingly, the computation burden of the central unit is significantly reduced while the control performances are identical. Besides, due to the reduced iteration number, the communication burden between local D-MPCs and central unit has been largely reduced. Therefore, this control structure is independent from the wind farm size and suitable for the modern wind farm application. 


\section{References}

[1] P. E. Sørensen, A. D. Hansen, F. Iov, F. Blaabjerg, and M. H. Donovan, Wind farm models and control strategies, 2005.

[2] J. Aho, A. Buckspan, J. Laks, P. Fleming, Y. Jeong, F. Dunne, M. Churchfield, L. Pao, and K. Johnson, "A tutorial of wind turbine control for supporting grid frequency through active power control," in American Control Conference (ACC), 2012. IEEE, 2012, pp. 3120-3131.

[3] B. Biegel, D. Madjidian, V. Spudic, A. Rantzer, and J. Stoustrup, "Distributed low-complexity controller for wind power plant in derated operation," in Control Applications (CCA), 2013 IEEE International Conference on. IEEE, 2013, pp. $146-151$

[4] H. Zhao, Q. Wu, S. Hu, H. Xu, and C. N. Rasmussen, "Review of energy storage system for wind power integration support," Applied Energy, 2014.

[5] Z. Lubosny and J. W. Bialek, "Supervisory control of a wind farm," Power Systems, IEEE Transactions on, vol. 22, no. 3, pp. 985-994, 2007.

[6] I. Munteanu, Optimal control of wind energy systems: towards a global approach.

[7] D. Madjidian, K. Martensson, and A. Rantzer, "A distributed power coordination scheme for fatigue load reduction in wind farms," in American Control Conference (ACC), 2011. IEEE, 2011, pp. 5219-5224.

[8] M. Soleimanzadeh, R. Wisniewski, and S. Kanev, "An optimization framework for load and power distribution in wind farms," Journal of Wind Engineering and Industrial Aerodynamics, vol. 107, pp. 256-262, 2012.

[9] F. Baccino, F. Conte, S. Grillo, S. Massucco, and F. Silvestro, "An optimal model-based control technique to improve wind farm participation to frequency regulation," 2014.

[10] J. Shu, B. Zhang, and Z. Bo, "A wind farm coordinated controller for power optimization," in Power and energy society general meeting, 2011 IEEE. IEEE, 2011, pp. 1-8.

[11] Y. Guo, W. Wang, C. Y. Tang, J. N. Jiang, and R. G. Ramakumar, "Model predictive and adaptive wind farm power control," in American Control Conference (ACC), 2013. IEEE, 2013, pp. 2890-2897.

[12] V. Spudić, M. Jelavić, and M. Baotić, "Wind turbine power references in coordinated control of wind farms," AutomatikaJournal for Control, Measurement, Electronics, Computing and Communications, vol. 52, no. 2, 2011.

[13] V. Spudic, M. Jelavic, M. Baotic, and N. Peric, "Hierarchical wind farm control for power/load optimization," The Science of making Torque from Wind (Torque2010), 2010.

[14] M. Soleimanzadeh and R. Wisniewski, "Controller design for a wind farm, considering both power and load aspects," Mechatronics, vol. 21, no. 4, pp. 720-727, 2011.

[15] T. G. Hovgaard, L. F. Larsen, J. B. Jorgensen, and S. Boyd, "Mpc for wind power gradients-utilizing forecasts, rotor inertia, and central energy storage," in Control Conference (ECC), 2013 European. IEEE, 2013, pp. 4071-4076.

[16] D. Halamay, M. Antonishen, K. Lajoie, A. Bostrom, and T. K. Brekken, "Improving wind farm dispatchability using model predictive control for optimal operation of grid-scale energy storage," Energies, vol. 7, no. 9, pp. 5847-5862, 2014.

[17] P. Giselsson, "Improving fast dual ascent for mpc-part i: The distributed case," arXiv preprint arXiv:1312.3012, 2013.

[18] _ _ "Improving fast dual ascent for mpc-part ii: The embedded case," arXiv preprint arXiv:1312.3013, 2013.

[19] J. M. Maciejowski, Predictive control: with constraints. Pearson education, 2002.

[20] T. Burton, N. Jenkins, D. Sharpe, and E. Bossanyi, Wind energy handbook. John Wiley \& Sons, 2011.

[21] X. Li, D. Hui, and X. Lai, "Battery energy storage station (bess)-based smoothing control of photovoltaic (pv) and wind power generation fluctuations," Sustainable Energy, IEEE Transactions on, vol. 4, no. 2, pp. 464-473, 2013.

[22] J. D. Grunnet, M. Soltani, T. Knudsen, M. Kragelund, and T. Bak, "Aeolus toolbox for dynamic wind farm model, simulation and control," in Proc. of the 2010 European Wind Energy Conference, 2010. 